\title{
LA CARICATURA EDITORIAL COLOMBIANA. UNA PERSPECTIVA SEMÁNTICA Y PRAGMÁTICA
}

\author{
Francia Martínez-Valencia
}

\begin{abstract}
RESUMEN
Las caricaturas editoriales han sido usadas como un instrumento de opinión, humor, sátira y por supuesto como un elemento de denuncia social y política a través de los años. Esta modalidad es, sin duda, una herramienta poderosa que generalmente emplea un dibujo y unas cuantas palabras o frases con el fin de transmitir un mensaje. De esta manera, el impacto de una caricatura radica ya sea en el dibujo, en el texto escrito o en ambos. El objetivo general de este artículo es hacer un análisis semántico y pragmático del discurso cotidiano de más de 126 caricaturas presentes en diferentes periódicos colombianos entre el 2010 y mayo del 2011. Los resultados generales de los análisis muestran que el ex presidente colombiano Álvaro Uribe es el personaje más retratado en las caricaturas mientras que la corrupción es el eje temático más frecuente. Finalmente, los términos o expresiones más empleados son las chuzadas, el Agro Ingreso Seguro, y los falsos positivos entre otras, mientras que los actos de habla que predominan son las afirmaciones, las preguntas y las exclamaciones.

Palabras clave: Caricatura colombiana, análisis del discurso, semántica y pragmática, léxico.
\end{abstract}

\begin{abstract}
Editorial cartoons have been used as a mechanism of opinion, humor, and satire and of course as a tool of political and social criticism for many years. They generally use a picture and text with the purpose of transmitting a message. Therefore the impact of the cartoons lies either in the picture or in the text or in both. The main purpose of this article is to analyze, from a semantic and pragmatic approach, the discourse of more than 126 cartoons from different Colombian newspapers between 2010 and May 2011. The main findings suggested that: a) the Colombian ex-President, Álvaro Uribe, is the most popular character in the cartoons, whereas corruption is the most frequent topic; b) The most common words used in the cartoons' discourse are chuzadas, Agro Ingreso Seguro, false positive; c) Finally, the most frequent speech acts used in the dialogues are assertions, questions and exclamations.
\end{abstract}

Key words: Colombian cartoons, discourse analysis, semantics and pragmatics, lexicon.

En un país donde la violación a los derechos humanos es constante, el poder de la palabra cobra vida como arma de lucha frente a los problemas sociales.

Gómez (2009)

Ph.D. Francia Martínez-Valencia. Profesora Asistente de Español. Departamento de Lenguaje, Cultura y Comunicación. University of Michigan-Dearborn.

Correo electrónico: femv@umd.umich.edu

Recepción: 28- 05- 2011

Aceptación: 20- 07- 2011 


\section{Introducción}

Una de las secciones en los periódicos nacionales que por lo general no pasa desapercibida para los lectores es la sección de la caricatura editorial. El lector es consciente de que allí puede enterarse en detalle de los personajes y temas más controversiales del momento, a la vez que puede burlarse y reírse de estos. Las caricaturas generan tanto interés que se han hecho estudios y análisis desde diversas disciplinas en diferentes países. Sin embargo, no existen estudios que se hayan enfocado en el análisis lingüístico, desde una visión semántica y pragmática, del discurso de la caricatura editorial colombiana en particular.

Se tiene conocimiento de un estudio reciente centrado en el análisis de la caricatura colombiana desde una perspectiva puramente económica (Villaveces y Rodríguez 2010) al igual que otro estudio, de carácter histórico, el cual revela los comienzos y el desarrollo de la caricatura en Colombia (González 1990). También, se sabe de un estudio hecho desde una perspectiva social y el cual describe el conflicto armado (Guerrilla, Paramilitares y Estado) en Colombia visto a través de los ojos de la caricatura editorial (Pachón 2009). A las anteriores temáticas, se añaden el análisis de las caricaturas colombianas desde una dimensión política (Colmenares 1984 y Acevedo 2009) y la caricatura como herramienta pedagógica en el aula de clase (Prieto y Paba 2008). Finalmente, cabe mencionar el estudio de Ayala (2008) el cual muestra de manera detallada las estrategias discursivas de las caricaturas, diseñadas por el diario colombiano El Tiempo, para representar la oposición como una amenaza inminente para la democracia y el estado ideal de cosas alcanzado por el Frente Nacional entre 1958 y 1974.

Es por eso que el presente estudio pretende ser un aporte valioso para los estudios lingüísticos sincrónicos del discurso de las caricaturas editoriales colombianas actuales, puesto que esta perspectiva no ha sido abordada en la elaboración de documentos y análisis de este país.

Se suele escuchar que Colombia es un país de contrastes, es decir, un país con una gran diversidad. Un país con cosas buenas como sus paisajes, su clima, su gente y su comida, pero también con cosas malas como el narcotráfico, los secuestros, la inseguridad y la corrupción entre muchos otros males más. El contraste anterior no es ajeno a los caricaturistas quienes se esfuerzan e incluso arriesgan sus vidas para destapar y ventilar, por medio del discurso de sus caricaturas, tanto lo negativo como lo positivo de la sociedad colombiana.

De acuerdo con Villaveces y Rodríguez (2010), el trabajo del lector de las caricaturas es entender y decodificar el contexto y los personajes en los cuales se dan estas caricaturas. Sin embargo, el análisis del discurso de la caricatura colombiana no se puede tomar a la ligera puesto que solamente aquellos que están al tanto de una realidad tan compleja, como la de este país, podrían identificar e interpretar sus situaciones y sus personajes de una manera más objetiva y contextualizada. Al respecto Gómez afirma que:

\footnotetext{
El problema social colombiano es reflejado insistentemente por el caricaturista, quien enlaza cada estereotipo con una dificultad y su causante. En un país donde la violación a los derechos humanos es constante, el poder de la palabra cobra vida como arma de lucha frente a los problemas sociales. Es allí donde los caricaturistas han recolectado historia por años, como instrumento constructor de la realidad. (2009: 18)
}

La caricatura, poco a poco, se ha convertido en un mecanismo por medio del cual se manifiesta la necesidad de opinar y sensibilizar a toda la sociedad sobre los graves problemas que ha afrontado Colombia durante toda su historia. A través de la riqueza de los diálogos y 
distintos recursos retóricos y visuales, el discurso de la caricatura llega a tener una función o rol social de gran impacto entre los lectores. Finalmente, la caricatura también muestra que a pesar de que Colombia padece tantos desequilibrios sociales la gente todavía se puede reír de estos.

\section{Breve historia de la caricatura colombiana}

Los inicios de la caricatura colombiana se remontan al siglo XIX (González 1990). De hecho, la primera caricatura de la cual se tiene conocimiento está representada en un grabado sobre la lucha entre los partidarios de Simón Bolívar y de Francisco de Paula Santander durante la convención de Ocaña o convención para reformar la Constitución de ese tiempo. Luego, se tiene registro de las caricaturas que aparecían en gacetas y diarios del siglo XIX contra los jefes españoles durante la reconquista. Sin embargo, es, en realidad, en el siglo XX en la década de los años 30, cuando la caricatura toma fuerza y auge (Villaveces y Rodríguez 2010). A este periodo de popularidad se le denominó "la edad de oro de la caricatura". Uno de los principales objetivos y temas de los caricaturistas en ese tiempo era la crítica política, sin descartar, por supuesto, los temas económicos y sociales como el desempleo y la pobreza. Entre los caricaturistas más reconocidos, de esa época, se puede mencionar a Chapete, Osuna, Vladdo y Pepón. Es, “[...] con estos caricaturistas que termina el período más glorioso de la caricatura colombiana. En ese momento se dieron las condiciones para ejercer la oposición desde la mesa del dibujante, lo que permitió hacer efectiva la creencia de que la caricatura es capaz de tumbar gobiernos" (González 1990: pp).

Actualmente, los caricaturistas más reconocidos en los periódicos nacionales son: Matador, Beto Barreto, Papeto, Mil, Pepón, Consuelo Lagos, Chócolo, Valmez, Jota, G, Rodrigo Guerreros, Carlos Esteban París, Bonil, entre otros. Gracias a estos talentosos caricaturistas los colombianos se mantienen en al tanto de los acontecimientos más controversiales en materia política y social. Sus caricaturas interactúan con el lector y lo invitan a conocer, a través del lenguaje gráfico y en ocasiones un texto, el trasfondo político, social y económico actual del país. Al igual que lo hacen los libros de historia, las caricaturas de estos autores pasan a ser parte de una especie de archivo histórico humorístico donde quedan registrados los hechos más sobresalientes del acontecer colombiano.

\section{Fundamentos teóricos}

Si bien el soporte fundamental de la caricatura es la utilización de la imagen no se puede negar que el texto también juega un papel crucial en el alcance e impacto de ésta (Joaquín Pardo en Durán 1990: 121). Es decir, los caricaturistas disponen tanto del texto y el lenguaje gráfico como estrategias discursivas para mostrar a los lectores la realidad del país desde una perspectiva generalmente humorística. Se puede observar, entonces, como la caricatura despliega una gama de recursos linguiísticos, retóricos, discursivos y gráficos con el fin de provocar una reacción en el lector (función apelativa del lenguaje) que ponga en entredicho los discursos oficiales. Desde esa perspectiva se asume, entonces, que los mensajes o textos presentes en la caricaturas están enmarcados en estudios que conciben el discurso como una práctica social o como un uso lingüístico contextualizado (Molero de Cabeza 2003).

El fundamento teórico del presente trabajo está enmarcado dentro del campo del análisis del discurso, un área de estudio que tiene como objetivo examinar las estructuras 
y funciones del texto y del habla en el contexto social, político y cultural (Van Dijk 1995). Se seguirá también la estructura de análisis semántico propuesto por Aguillón y Palencia (2006) la cual se deriva originalmente del modelo semántico de B. Pottier (1992 y 1993). A continuación, se describen los parámetros de análisis de este artículo partiendo de los lineamientos formulados por los autores mencionados previamente. Primero que todo, se identificarán los personajes caricaturizados con mayor frecuencia (nivel conceptual). Luego, se identificarán los ejes temáticos (nivel conceptual) y los acontecimientos ocurridos en el país (nivel referencial/mundo real o imaginario) más sobresalientes en el discurso cotidiano de las caricaturas colombianas. Posteriormente, a nivel semántico y pragmático, se mostrarán los campos léxico-semánticos presentes en el discurso de las caricaturas y los actos de habla más frecuentes usados en los diálogos de los personajes.

Atendiendo a los fundamentos teóricos mencionados previamente se llevará a cabo el análisis de las caricaturas publicadas en diferentes periódicos nacionales colombianos. Es claro que para una correcta interpretación y asimilación de los mensajes contenidos en las caricaturas editoriales los lectores deberán estar al tanto de los acontecimientos nacionales, en este caso, de Colombia. Lo anterior es el mecanismo que Eco (1992) ha denominado como pragmática textual. Se toma entonces como principio básico el análisis del aspecto semántico de las caricaturas y luego el sentido que estas adquieren en el contexto social. Con este estudio, el lector podrá darse una idea del discurso, temas, situaciones, personajes, léxico, recursos retóricos y actos de habla más representativos de la compleja realidad Colombia, reflejados a través de las caricaturas.

\section{Metodología}

Para cumplir con el propósito de este estudio, se reunió una muestra constituida por más de 126 caricaturas editoriales sacadas, de las ediciones de los años 2010 y mayo de 2011, de cuatro periódicos colombianos reconocidos: El Tiempo, El Colombiano y El Espectador respectivamente. Una vez seleccionadas las 126 caricaturas se procedió a clasificarlas temáticamente para facilitar su análisis.

\section{Análisis del corpus y resultados del análisis}

\subsection{Personajes más caricaturizados: nivel conceptual}

La Tabla 1 nos resume quiénes son los personajes más retratados presentes en las caricaturas de los periódicos nacionales colombianos:

Tabla 1. Personajes caricaturizados y frecuencia de aparición

\begin{tabular}{|l|l|}
\hline Personajes & Frecuencia \\
\hline El ex presidente de Colombia Álvaro Uribe Vélez & 32 \\
\hline El presidente actual de Colombia: Juan Manuel Santos & 25 \\
\hline El presidente de Venezuela: Hugo Chávez & 14 \\
\hline Los damnificados de las inundaciones & 12 \\
\hline La ex senadora destituida del congreso: Piedad Córdoba & 9 \\
\hline
\end{tabular}




\begin{tabular}{|l|l|}
\hline Ladrones & 9 \\
\hline El alcalde destituido de Bogotá: Samuel Moreno & 8 \\
\hline $\begin{array}{l}\text { El grupo familiar Nule: Miguel Nule Velilla, Manuel Nule Velilla y Guido } \\
\text { Nule Marino }\end{array}$ & 7 \\
\hline Funcionarios de DAS (Departamento Administrativo de Seguridad) & 7 \\
\hline El presidente de Estados Unidos: Barack Obama & 7 \\
\hline El Tío Sam & 4 \\
\hline Borrachos o ebrios & 4 \\
\hline El hermano del alcalde destituido de Bogotá (Samuel Moreno): Iván Moreno & 4 \\
\hline $\begin{array}{l}\text { Miembros y cabecillas principales del grupo guerillero las FARC (Fuerzas } \\
\text { Armadas Revolucionarias de Colombia): Manuel Marulanda alias Tirofijo, } \\
\text { el Mono Jojoy y Cano. }\end{array}$ & 3 \\
\hline Miembros del Ejército de Colombia & 3 \\
\hline Jesucristo & 1 \\
\hline Ratas & 1 \\
\hline Lobo & 1 \\
\hline Vacas & 1 \\
\hline
\end{tabular}

El análisis muestra que el ex presidente Álvaro Uribe (ver Figura 1) se consagra como el personaje colombiano más caricaturizado debido a los múltiples escándalos de corrupción que dejó su administración. Por eso, no es raro que los caricaturistas se esfuercen por denunciar y recordar al público lector los detalles más controversiales de su mandato. Luego aparece, en segundo lugar, el presidente actual de Colombia Juan Manuel Santos (ver Figura 2). A pesar de que Santos también estuvo bajo la administración de Álvaro Uribe, su presencia en las caricaturas se centra en temas como las relaciones diplomáticas con Venezuela, su amistad con Álvaro Uribe y el problema de las inundaciones por el fenómeno climático de la Niña.

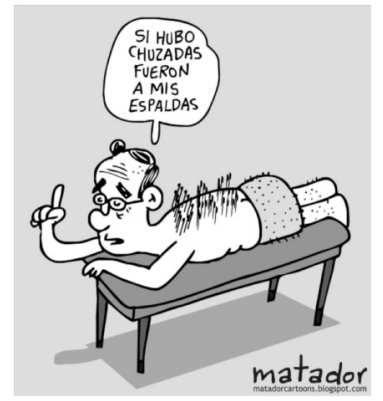

Figura 1

El Tiempo, Matador (02-25- 2010)

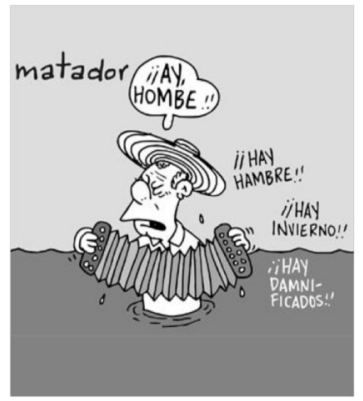

Figura 2

El Tiempo, Matador (01-16-2011)

Paradójicamente, el puesto número tres no lo ocupa una figura del ámbito nacional sino internacional. En este caso, se hace referencia al presidente actual de Venezuela, Hugo Chávez (ver Figura 3). Su presencia en las caricaturas colombianas está justificada por dos razones principalmente. La primera razón tiene que ver con las delicadas relaciones diplomáticas entre Colombia y Venezuela mientras que la segunda está conectada con su supuesto vínculo de amistad con jefes del grupo guerrillero de las FARC. Más adelante, 
también a nivel internacional, se observa la presencia del presidente actual de Estados Unidos, Barack Obama y el Tío Sam (ver Figura 4). Su presencia se debe, primordialmente, a las múltiples conversaciones y peticiones que se han sostenido para la aprobación del Tratado de Libre Comercio, entre Colombia y Estados Unidos, y la posibilidad de construcción de bases militares estadounidenses en territorio colombiano.

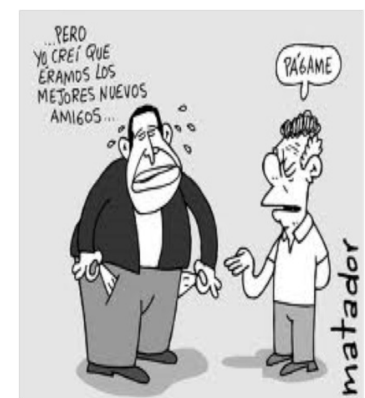

Figura 3

El Tiempo, Matador (04-03-2011)

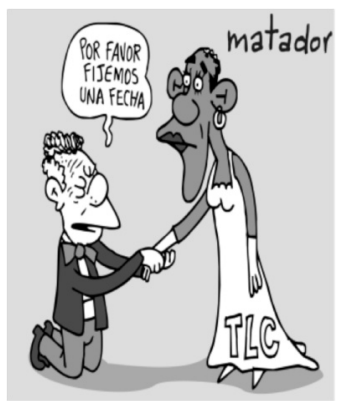

Figura 4

El Tiempo, Matador (03-07-2011)

Otros protagonistas dentro de las caricaturas, no pertenecientes al ámbito político, lo constituyen las miles de personas afectadas por el crudo invierno que ha azotado a Colombia durante el 2010 y parte del 2011 (ver Figura 5). Luego, le siguen nuevamente dos figuras políticas, el ex alcalde de Bogotá, Samuel Moreno y la ex senadora, Piedad Córdoba, ambos, destituidos de sus cargos públicos. El primero por supuestos fraudes de corrupción y la segunda por colaborar con las Fuerzas Armadas Revolucionarias de Colombia (FARC), (ver Figura 6).

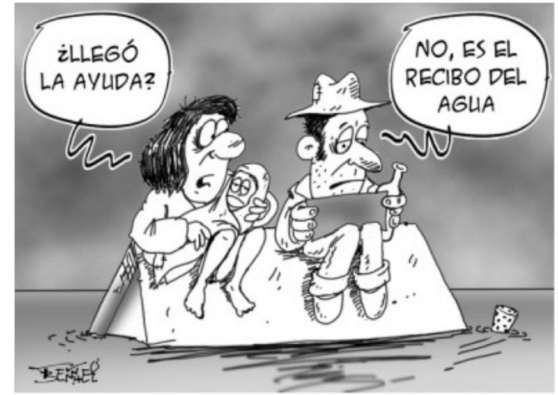

Figura 5

Caricaturas de Colombia, Bennael (12-14-2010)

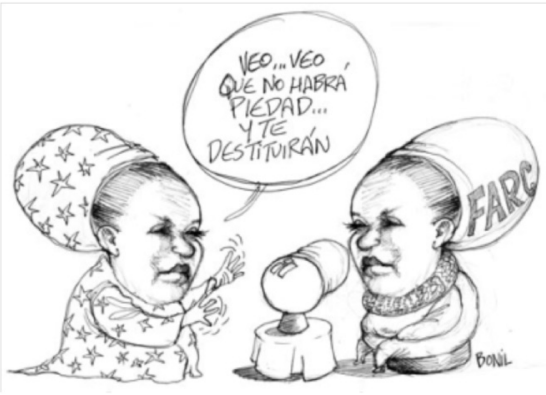

Figura 6

Caricatura periodística, Bonil (09-28-2010)

Más adelante aparecen, nuevamente, otros funcionarios investigados por casos de corrupción. Estos son el grupo familiar de construcción Nule, el hermano del ex alcalde de Bogotá, Iván Moreno y miembros del DAS (Departamento Administrativo de Seguridad). En cuanto al tema de la violencia, tenemos la presencia de miembros del grupo guerrillero las FARC, seguidos de miembros del Ejército Colombiano y acusados de matanzas de civiles inocentes. Por otro lado, en el tema de la inseguridad se destaca la figura de los ladrones. Cierra el grupo de personajes los borrachos al volante, Jesucristo como el símbolo de esperanza entre los damnificados de las inundaciones y las ratas como símbolo del hurto de dineros públicos. En Colombia, la palabra rata se usa también como sinónimo de ladrón. Por último, y aunque no tan frecuente, los caricaturistas colombianos también hacen uso de figuras de animales, como el lobo y la vaca, en sus discursos. 


\subsection{Los temas y acontecimientos más frecuentes: nivel conceptual y nivel referencial}

Los ejes temáticos y acontecimientos más importantes en torno a los cuales gira el discurso de las caricaturas colombianas son los siguientes:

Tabla 2. Ejes temáticos con sus respectivos acontecimientos y frecuencia de aparición

\begin{tabular}{|l|l|l|}
\hline Ejes temáticos & Acontecimientos & Frecuencia \\
\hline La corrupción & $\begin{array}{l}\text { El escándalo de las chuzadas del DAS } \\
\text { El escándalo del Agro Ingreso Seguro(AIS) } \\
\text { El Carrusel o el Cartel de los Contratos } \\
\text { Enriquecimiento ilícito del grupo Nule } \\
\text { Inscripción de cédulas falsas o de personas fallecidas para votar }\end{array}$ & 37 \\
\hline $\begin{array}{l}\text { Las relaciones } \\
\text { diplomáticas con } \\
\text { Venezuela }\end{array}$ & $\begin{array}{l}\text { La relaciones diplomáticas entre el presidente de Venezuela Hugo } \\
\text { Chávez, el ex presidente de Colombia Álvaro Uribe, el presidente } \\
\text { actual, Juan Manuel Santos y la ex senadora Piedad Córdoba }\end{array}$ & 13 \\
\hline $\begin{array}{l}\text { Las relaciones } \\
\text { políticas internas }\end{array}$ & $\begin{array}{l}\text { La relación entre el ex presidente Álvaro Uribe y el presidente actual } \\
\text { Juan Manuel Santos }\end{array}$ & 7 \\
\hline La violencia & $\begin{array}{l}\text { La inseguridad: robos y atracos } \\
\text { Caso de los falsos positivos } \\
\text { Conductores ebrios o borrachos al volante } \\
\text { La violación a los derechos humanos }\end{array}$ & 19 \\
\hline La economía & El Tratado de Libre Comercio (TLC) con Estados Unidos & 14 \\
\hline Los desastres naturales & $\begin{array}{l}\text { El invierno y las inundaciones del 2010 y del 2011 } \\
\text { El fenómeno climático de la Niña }\end{array}$ & 13 \\
\hline
\end{tabular}

Se identificaron 6 ejes temáticos en el discurso de las caricaturas colombianas. El primer tema que sobresale es de la corrupción, el cual se ha convertido en uno de los principales flagelos que carcome las finanzas públicas y la credibilidad del Estado Colombiano. Este problema, sin duda alguna, se refleja en la vasta mayoría de las caricaturas analizadas. Desafortunadamente, el Estado está, ahora más que nunca, en el ojo del huracán por escándalos de corrupción de muchos de sus funcionarios, especialmente aquellos que estuvieron bajo la administración del ex presidente Álvaro Uribe. La siguiente caricatura (ver Figura 7) es un buen ejemplo del la grave situación que afronta Colombia en este aspecto:

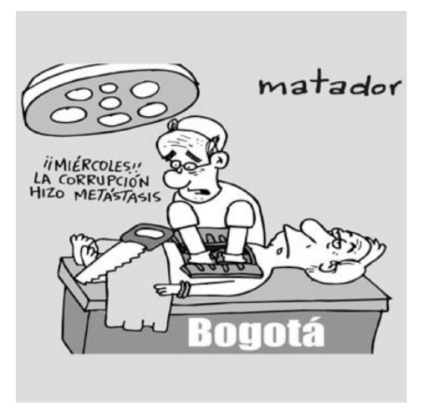

Figura 7

El Tiempo, Matador (05-24-2010)

Dentro de los principales hechos y acontecimientos presentes en este eje temático se destacan los siguientes: en primera instancia, los escándalos de las chuzadas o espionaje 
telefónico del cual fueron víctimas importantes figuras del Estado. Las investigaciones de la Fiscalía Colombiana apuntan a que el ex presidente Álvaro Uribe tenía conocimiento de esta práctica ilegal. En segundo lugar, se tiene lo que se ha denominado como El Cartel o Carrusel de la Contratación. Este hecho tiene que ver con beneficios económicos que, supuestamente, recibieron varios funcionarios del Estado, durante el proceso de concesión de contratos destinados a la construcción de grandes obras públicas en Bogotá. Se presume que estos empleados recibieron fuertes sumas de dinero provenientes de las compañías a las cuales ellos les otorgaron esos contratos públicos (ver Figura 8 y 9).

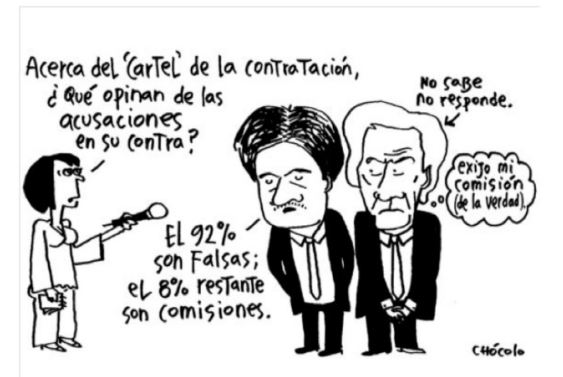

Figura 8

El Espectador, Chócolo (11-04-2010)

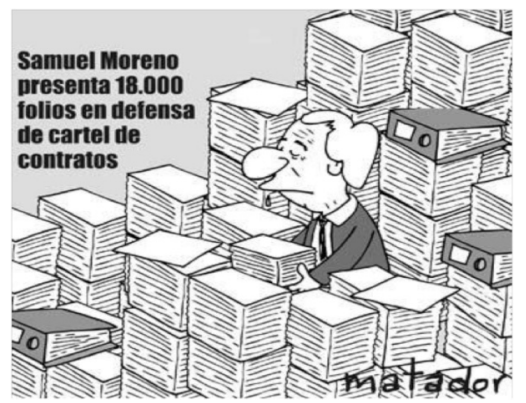

Figura 9

El Tiempo, Matador (10-24-2010)

Los caricaturistas también muestran con frecuencia el polémico caso de enriquecimiento ilícito del grupo familiar de construcción de obras llamado los Nule. La Fiscalía los ha acusado de enriquecerse con dineros públicos gracias al otorgamiento de contratos, de manera irregular, para la construcción de varias megaobras en Bogotá. Finalmente, para cerrar el eje temático de la corrupción, se menciona el caso del Agro Ingreso Seguro en el cual se vieron involucradas varias figuras del ámbito político y social. Se cree que estas personas recibieron dineros públicos, destinados originalmente para los campesinos de bajos recursos y sus cultivos. Esta irregularidad, al igual que las anteriores, se cometió bajo la administración del ex presidente Álvaro Uribe.

Continuando con otros ejes temáticos, las relaciones diplomáticas con Venezuela ocupan el segundo plano para los caricaturistas. Estos hacen énfasis en dos aspectos que siempre han sido causantes de conflictos políticos entre las dos naciones. La primera situación es la supuesta conexión de Hugo Chávez con el grupo guerrillero colombiano de las FARC. Este vínculo, a su vez, ha conllevado a relaciones tensas entre Chávez, Uribe y el presidente actual de Colombia, Juan Manuel Santos.

Otro tema que prevalece en las caricaturas lo constituye la violencia, en este caso concreto la ola de inseguridad, que vive Bogotá y Cali principalmente (ver Figura 10).

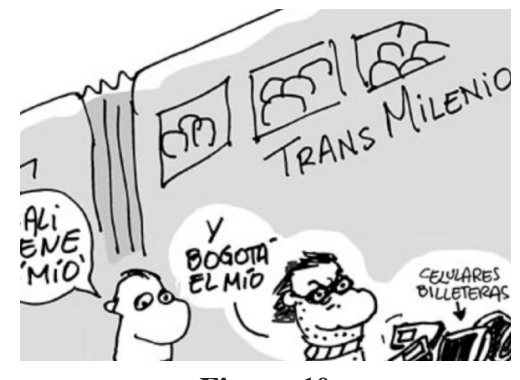

Figura 10

Palosa blogspot, Palosa (02-03-2011) 
Al anterior problema se suman el incremento acelerado de conductores ebrios y de víctimas fatales, a causa de esto, en las carreteras del país. Por otro lado, tenemos el tema de la violación de los derechos humanos, por parte del Estado Colombiano, el cual se ve reflejado en los casos de falsos positivos bajo el gobierno de Álvaro Uribe. La práctica anterior hace referencia a la matanza de civiles inocentes por parte del Ejército Colombiano. Las investigaciones al respeto revelan que varios civiles eran disfrazados como guerrilleros o paramilitares y luego presentados como tales ante los medios de comunicación.

En cuanto el eje temático de la economía, los caricaturistas resaltan las infructuosos esfuerzos del gobierno colombiano en relación con la firma del Tratado de Libre Comercio con Estados Unidos. Finalmente, el tema de los desastres naturales también está presente en las caricaturas. Entre los principales acontecimientos, se tienen las graves inundaciones y los estragos causados por el fenómeno climático de la Niña en diferentes regiones de la geografía colombiana. Los caricaturistas denuncian en sus discursos la negligencia y la demora de las ayudas, por parte del gobierno, para los miles de damnificados en el país.

Por último, y por sorprendente que parezca, entre las caricaturas seleccionadas no hubo ninguna que hiciera referencia al fenómeno del narcotráfico como habría de esperarse. También, se observó que hay pocas caricaturas, en esta muestra de 126, que hablen del secuestro, otro de los grandes temas de la sociedad colombiana. Al parecer, en la actualidad, el tema de la corrupción es tan serio y grave que ha opacado las dos temáticas mencionadas previamente.

\subsection{Campos léxico-semánticos de las caricaturas colombianas: nivel lingüístico}

A nivel lingüístico, los resultados del análisis arrojan la siguiente información en cuanto a los campos léxico-semánticos presentes en los diálogos de los personajes caricaturizadas. La Tabla 3 resume esta parte en detalle:

Tabla 3. El léxico de los textos de las caricaturas

\begin{tabular}{|c|c|}
\hline Campo semántico & Discurso y léxico asociado \\
\hline La corrupción & $\begin{array}{l}\text { "Ni pa' llá ni pa'ca: Estatuto anticorrupción" } \\
\text { "Los Nule se desataron en quiebra: La pobre viejecita sin nada que comer" } \\
\text { "Abuelita iqué micrófonos tan grandes tienes!", "Son para oírte (espiarte) mejor" } \\
\text { "Si Colombia pudiera exportar su corrupción... seríamos millonarios" } \\
\text { "Yo siempre me he lavado las manos" "parapolítica, falsos positivos, tráfico de influ- } \\
\text { encias, reelección" } \\
\text { "iiMentiroso!!" "iCorrupto!!" } \\
\text { "iMiércoles!!, la corrupción hizo metástasis" } \\
\text { "Miembros de prestantes familias beneficiarios del AIS habrían presentado docu- } \\
\text { mentos falsos" } \\
\text { "Si hubo chuzadas fueron a mis espaldas" } \\
\text { "Otra lamentable página es la historia de los desfalcos de la nación" } \\
\text { "Democracia es cuando un ciudadano puede elegir libremente al candidato que más } \\
\text { platica le dé por su voto" } \\
\text { "Vuelve y juega: inscripción de cédulas" } \\
\text { "Y como ya son ricos ni modo de acusarlos de enriquecimiento ilícito" } \\
\text { "Payasos, aromaterapia y lechona para los } 46 \text { militares sindicados de falsos positivos" } \\
\text { "Si cada semana meten a la cárcel a dos o tres uribistas... me voy a quedar solo" } \\
\text { “iAuxilio!!, mi hermanito se cayó del carrusel" }\end{array}$ \\
\hline
\end{tabular}




\begin{tabular}{|c|c|}
\hline Las inundaciones & $\begin{array}{l}\text { "S.O.S" } \\
\text { "La niña II" } \\
\text { "Tan lindos, tan elegantes, tan enamorados... y tan secos" } \\
\text { "Vaya, pasamos de ser la Atenas suramericana, a la Venecia suramericana" } \\
\text { "De ahora en adelante algunas regiones cambiarán de nombre...Atlántico será la } \\
\text { Atlántida" } \\
\text { "Esta tarde vi llover, vi gente correr y no estabas tú" } \\
\text { "Mira el nene dijo sus primeras palabritas" "...Glu...Glu...Glu" } \\
\text { "Llegó la ayuda" "No es el recibo del agua". }\end{array}$ \\
\hline La inseguridad & $\begin{array}{l}\text { "Pero al menos podernos viajar seguros por carretera" } \\
\text { "No tengo trabajo... no tengo nada... Entonces cómpreme el cuchillo" } \\
\text { "Y qué opina del incremento de los asaltos en Bogotá?", } \\
\text { "En cuanto a su pregunta...creo que esta ola de inseguridad es muy grave" } \\
\text { "Y pensar que uno antes sobrevivía con tres atracos diarios" } \\
\text { "Y qué poderosa razón lo motivó a no sacar su carro hoy?": "Me lo robaron" }\end{array}$ \\
\hline La economía & $\begin{array}{l}\text { "Revivieron el TLC" } \\
\text { "Mesero: Tamal, Lechona y Cuchuco"/ "Tampoco tenemos ese TLC en el menú." } \\
\text { "¿T.L.C?" "No, we can’t" } \\
\text { "Mamá, ¿Qué será lo que quiere el negro? (Obama)" "TLC" } \\
\text { "Bases" "TLC" } \\
\text { "Si me porto bien y hago todas las tareas es posible que al final de este año sea } \\
\text { aprobado (TLC)" }\end{array}$ \\
\hline Las relaciones políticas & $\begin{array}{l}\text { "Los mejores amigos" } \\
\text { "Un amigo se alejará este año" } \\
\text { "Darse un regalo mutuo" } \\
\text { "Cuál distanciamiento?" } \\
\text { "Me voy a quedar solo" } \\
\text { "Yo creí que éramos los nuevos mejores amigos" "págame" } \\
\text { "Por ser un hombre tranquilo y prudente en sus palabras...para mí es el hombre más } \\
\text { grande de América" (Chávez) }\end{array}$ \\
\hline La violencia & $\begin{array}{l}\text { "¿Derechos humanos?” "al fondo a la derecha” } \\
\text { “Tipo de sangre?” “Falso positivo!” } \\
\text { “iA ver!! ¿Dónde están los secuestrados?: ¿Dónde están?” } \\
\text { "Los de las FARC no son malos muchachos... Lo que pasa es que a veces se pasan } \\
\text { de la rayita” }\end{array}$ \\
\hline
\end{tabular}

Como se puede apreciar, la Tabla 3 agrupa 6 campos léxico-semánticos que surgen del discurso de las caricaturas seleccionadas. El análisis muestra el predominio de una serie de palabras y expresiones que han surgido debido a la compleja realidad social y política del país. Entre estas palabras y términos tenemos los siguientes (ver también Figura 11):

a) Agro Ingreso Seguro: nombre dado a la supuesta desviación o robo de fondos monetarios públicos para ayudar a los campesinos de escasos recursos en sus cultivos. Supuestamente estos dineros fueron a parar a las arcas de los grandes productores o terranientes, en lugar de ir a los campesinos menos favorecidos.

b) Chuzadas: se usa este término para referirse al espionaje telefónico de parte de miembros del gobierno nacional, específicamente el DAS (Departamento Administrativo de Seguridad).

c) Chicharrrones: esta palabra es sinónimo de problemas difíciles de resolver.

d) Falsos positivos: este término ha estado muy de moda en los últimos años en Colombia. Se refiere a declarar un resultado positivo del ejército colombiano a algo que no lo es. 
Puede ser el montaje de auto-atentados de los cuales culpan a las fuerzas insurgentes o la guerrilla, puede ser la supuesta frustración de algún plan terrorista por parte del ejército, o pude ser culpar de una masacre cometida por terceros a las guerrillas.

e) Carrusel o Cartel de los Contratos: De esta manera se le ha denominado a corrupción por parte de algunos alcaldes y funcionarios públicos en la concesión contratos para la construcción de grandes obras. Se cree que estos empleados recibieron fuertes sumas de dinero, de forma ilegal, provenientes de las compañías a las cuales ellos les otorgaron esos contratos.

f) Parapolítica: Se denomina así a las figuras del ámbito político que están o han estado involucradas con los paramilitares. En Colombia, son designados como paramilitares, autodefensas, paras, paracos y masetos los grupos armados al margen de la ley y enemigos de la guerrilla.

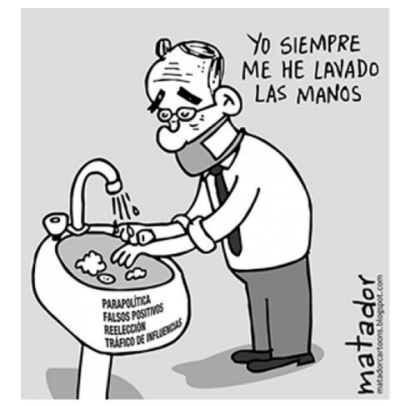

Figura 11

El Tiempo, Matador (02-15-2010)

Con respecto a la presencia del léxico anterior, Patiño (2004) resalta la gran influencia de los medios de comunicación colombianos en cuanto a la creación y uso de palabras y expresiones coloquiales para referirse a la realidad del país. Añade que la prensa, la radio y la televisión no solamente ejercen poder en la formación de una opinión pública y en el refuerzo de determinados valores sociales, sino también, como es apenas normal, en los hábitos lingüísticos de las personas. Es así como los hechos más complejos de la realidad colombiana se ven manifestados a través de palabras y expresiones impuestas, en su mayoría, por el poder de la prensa nacional (Ayala 2007).

En cuanto al uso de algunos recursos retóricos se puede apreciar el empleo de onomatopeyas “...Glu..., Glu..., Glu..." y las comparaciones fonéticas, "Atlántico versus Atlántida", para burlarse y denunciar los estragos del invierno (ver Figura 12 y 13). Igualmente, se nota el empleo de la onomatopeya de Navidad de Papá Noel "Jo Jo Joy" para denunciar la supuesta conexión del presidente Chávez con "El Mono Jojoy”, el ex líder del grupo guerrillero de las FARC (ver Figura 14).

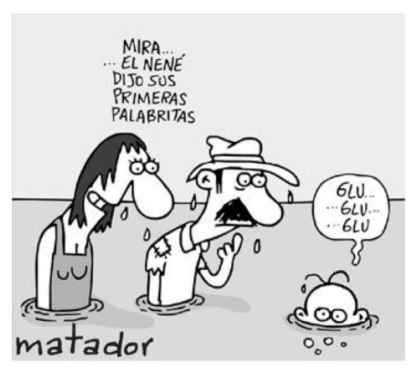

Figura 12

El Tiempo, Matador (04-19-2011)

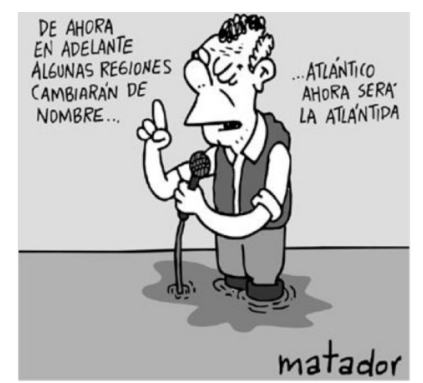

Figura 13

El Tiempo, Matador (04-25-2011)

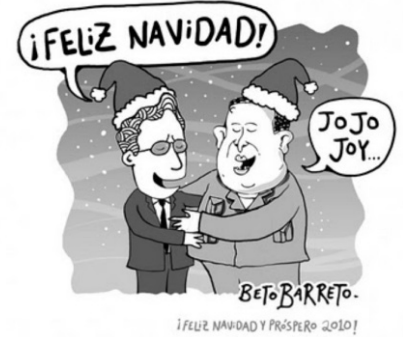

Figura 14

El Tiempo, Matador (12-06-2009) 
Por otro lado, se observa el uso constante de las comparaciones en los ejes temáticos tales como la corrupción: "Miércoles, la corrupción hizo metástasis" y "La corrupción nace, crece, se reproduce, pero no muere... se transforma". El uso de partes de canciones y frases famosas colombianas, como "La cumbia del Africano" de la agrupación la Sonora Dinamita, "Esta tarde vi llover" del cantante mexicano Armando Manzanero" y la expresión usada en los vallenatos "ay Hombre", constituyen otros de los recursos lingüísticos que emplean los caricaturistas para burlarse y denunciar lo diario del acontecer nacional (ver Figura 15 y 16).

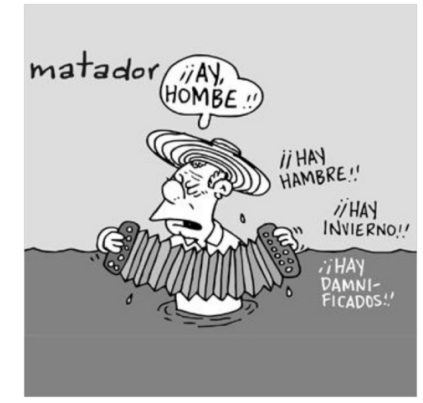

Figura 15

El Tiempo, Matador (01-16-2011)

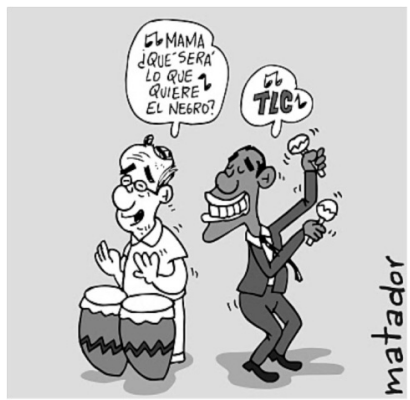

Figura 16

Por supuesto, el recurso de la ironía no podía faltar en el discurso de las caricaturas. Un ejemplo claro de la figura anterior es la burla que hacen los caricaturistas del caso de corrupción del grupo familiar Nule. Se cree que estas personas serían recluidas no en una cárcel de máxima seguridad y peligrosa como La Picota sino, por el contrario, en sus lujosos domicilios (programa casa por cárcel) o prisiones construidas especialmente para ellos. Se emplea, entonces, la ironía para criticar y burlarse de las fallas y la corrupción dentro del mismo sistema judicial colombiano (ver Figura 17). Otro elemento retórico, presente en el discurso de la caricatura para denunciar los casos de espionaje telefónico, lo constituyen las partes de cuentos famosos como el de La Caperucita Roja: "Abuelita iqué micrófonos tan grandes tienes! Son para oírte mejor".

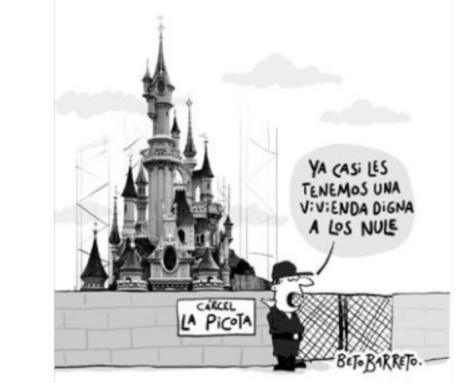

Figura 17

El Tiempo, Beto Barreto (04-21-2011)

\section{4. Actos de habla empleados en los diálogos de las caricaturas colombianas}

A nivel pragmático, tenemos los actos de habla definidos como las acciones que se pueden llevar a cabo con el solo uso de las palabras en una situación comunicativa (Austin 1975). A continuación, se da un ejemplo de lo que es un acto de habla de la vida cotidiana, entre un profesor y uno de sus estudiantes pidiendo más tiempo para entregar un trabajo: 
Pedir: Profesor, no pude terminar el trabajo. ¿Se lo puedo dar la próxima clase?

Conceder: Está bien.

Advertir-amenazar: [...] pero que no vuelva a pasar. Porque sabes muy bien [...]

Prometer: Se lo juro, profe, no vuelve a pasar.

Justificar - dar excusas: Es que anoche tenía dolor de estómago y no pude concentrarme [...]

El diálogo anterior muestra todas las cosas que pueden lograr los seres humanos con sus palabras en un intercambio comunicativo cotidiano. Otros ejemplos de actos de habla son saludar; solicitar u ofrecer información; aseverar o enunciar; pedir y ofrecer disculpas; expresar indiferencia, agrado o desagrado; expresar estados de ánimo; intimidar y prometer entre muchos otros más.

En general, el análisis de los diálogos de las caricaturas colombianas analizadas revela que los actos de habla empleados con mayor frecuencia son: en primer lugar afirmar (42) seguido de la acción de preguntar (19). Luego, tenemos acciones como exclamar (14), pedir o exigir (7), negar (5), ordenar (4), ofrecer (2) y aclarar o explicar (2). Por último, aparecen otros actos de habla como prometer (1), predecir (1), recomendar (1), denunciar (1), defenderse (1) y alagar (1). A continuación, se muestran dos ejemplos (ver Figuras 18 y 19).

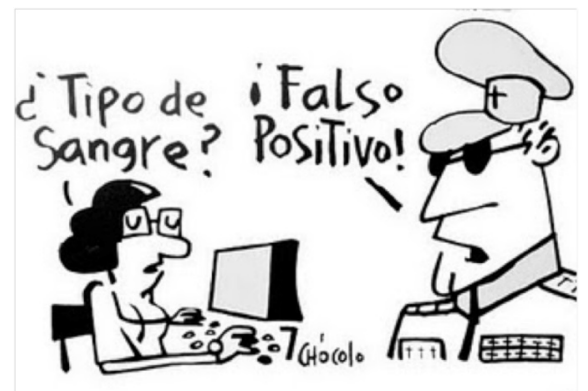

Figura 18

El Espectador, Chócolo (01-08-2010)

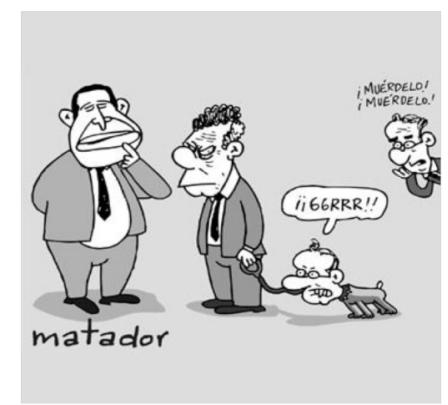

Figura 19

El Tiempo, Matador (02-13-2011)

\section{Conclusiones}

El recorrido por más de 126 caricaturas ofrece una radiografía y panorama de muchos de los males que, desafortunadamente, aquejan a Colombia desde los últimos años. Haciendo uso de una serie dibujos, un lenguaje explícito, burlesco, satírico e irónico, los caricaturistas sacan provecho de su talento e imaginación para atreverse a denunciar y a mostrar los problemas sociales actuales a través del discurso humorístico. El análisis de las caricaturas colombianas ha permitido llegar a las siguientes conclusiones generales:

a) Es evidente que los personajes caricaturizados que aparecen con mayor frecuencia en la caricatura colombiana son las figuras del ámbito político. Entre los más retratados está el ex presidente de Colombia Álvaro Uribe seguido del presidente actual Juan Manuel Santos. A nivel internacional se destacan figuras políticas tales como el presidente de Venezuela, Hugo Chávez, y el presidente de Estados Unidos, Barack Obama. Finalmente, a nivel local, sobresalen el ex alcalde de Bogotá, Samuel Moreno, su hermano, Iván Moreno y la ex senadora, Piedad Córdoba.

b) Los ejes temáticos más destacados son, sin duda alguna, la corrupción como número uno, seguida de las relaciones diplomáticas con Venezuela. Luego, aparecen la violencia, los desastres naturales y finalmente los temas económicos. 
c) Los acontecimientos políticos y sociales más sobresalientes son el escándalo de las chuzadas del DAS o espionaje telefónico, el escándalo del Agro Ingreso Seguro o desviación de dineros públicos y el enriquecimiento ilícito con dineros públicos de parte del grupo Nule. Junto a los hechos anteriores, se suman las inundaciones causadas por el fenómeno climático de la Niña y la inseguridad que afecta a las grandes ciudades como Bogotá y Cali. Por último, tenemos la posibilidad de la firma y cierre del Tratado de Libre Comercio (TLC) con Estados Unidos y la irresponsabilidad de conductores ebrios, al volante, en las carreteras del país.

d) A nivel léxico y semántico, los textos del discurso de la caricatura colombiana revelan el empleo constante de palabras y términos que han surgido para denominar varios acontecimientos, políticos y sociales, específicos Colombia. El término más común es el de las chuzadas, seguido del término Agro Ingreso Seguro y falsos positivos. Luego, aparece el empleo de palabras y expresiones como chicharrones y el Carrusel o Cartel de los Contratos. También, se observa el empleo de figuras retóricas en los diálogos de las caricaturas. Sobresalen, en este caso, las onomatopeyas, las comparaciones, la ironía, el uso de partes de canciones y de cuentos infantiles populares.

e) Finalmente, a nivel pragmático, los diálogos entre los personajes de las caricaturas muestran acciones como afirmar, preguntar, exclamar y pedir o exigir como los actos de habla más frecuentemente empleados.

Como se ha podido apreciar a lo largo de este estudio, las caricaturas no solamente ofrecen un panorama político y social de lo que es un país, en este caso Colombia, sino que también muestran la riqueza lingüística presente en los diálogos de los personajes caricaturizados. Es indudable, entonces, que las caricaturas constituyen una valiosa fuente para los estudios lingüísticos sincrónicos del discurso caricaturesco.

\section{Bibliografía}

Acevedo, Darío. 2009. "Política y caudillos colombianos en la caricatura editorial, 19201950". Historia y Sociedad. 17: 237-282.

Austin, John. 1975. How to do things with words. Cambridge: Harvard University Press.

Aguillón, Pedro y Palencia, Pedro. 2006. "La cotidianidad del venezolano en la prensa humorística regional: un estudio semántico y pragmático”. Revista Opción. 22: 68-86.

Ayala, Cesar. 2008. "Exclusión, discriminación y abuso de poder en El Tiempo del Frente Nacional: una aproximación desde el análisis crítico del discurso (ACD)". Colombia: Universidad Nacional de Colombia Bogotá.

Ayala, German. 2007. "En medios de comunicación en Colombia: De la acción informativa a la acción política". http://laotratribuna1.blogspot.com/2007/05/medios-de-comunicacinen-colombia-de-la.html.

Bennael. 2010. Caricaturas de Colombia. http://caricaturascolombia.blogspot.com/

Barreto. 2011. “Imágenes sin título”.Caricaturistas, El Tiempo.com. http://www.eltiempo.com/ 
Bonil. 2010. Bonil: Caricatura periodística. http://bonilperiodismo.blogspot.com/2010/09/ piedad-cordoba.html.

Chócolo. 2011. "Imágenes sin título”. El Espectador.com. http://www.elespectador.com/

Colmenares, German. 1984. "Ricardo Rendón: una fuente para la historia de la opinión pública”. Colombia: Fondo Cultural Cafetero.

Durán, Milagros. 1990. “La caricatura en la prensa nacional”. Trabajo de Licenciatura: Universidad Central de Venezuela.

Eco, Umberto. 1992. Los límites de la interpretación. Barcelona: Lumen.

Matador. 2010-2011. "Imágenes sin título”. Caricaturistas, El Tiempo.com. http://www. eltiempo.com/

Gómez, Astrid. 2009. "Análisis semiolingüístico de la caricatura de Antonio Caballero". Revista de comunicación e información. 1: 1-20.

González, Beatriz. 1990. Tercera dimensión de la historia. La caricatura política en Colombia. En 160 años, crítica y humor: otra manera de juzgar los hechos. Biblioteca Virtual del Banco de la República de Colombia. http://www.banrepcultural.org/blaavirtual/ revistas/credencial/octubre1990/octubre1.htm.

Molero de Cabeza, Lourdes. 2003. "El enfoque semántico-pragmático en el análisis del discurso. Visión teórica actual”. Lingua Americana. 12: 5-28.

Pachón, Juan. 2009. En el conflicto armado interno en la caricatura editorial. http://www.scribd. com/doc/48249475/EL-CONFLICTO-INTERNO-ARMADO-COLOMBIANO-ENLA-CARICATURA-EDITORIAL.

Palosa. 2011. "Palosa". http://palosa.blogspot.com/

Patiño, Carlos. 2004. “Aspectos del lenguaje en Colombia”. CES. 4: 1-22.

Pottier, Bernard. 1992. Teoría y análisis en lingüística. Madrid: Gredos.

1993. Semántica general. Madrid: Gredos.

Prieto, Samuel y Paba, Zuany. 2008. "El uso de cuentos y caricaturas para la enseñanza de ideas dinámico sistémicas en el ámbito infantil y empresarial”. Revista Praxis Educativa. 1: 45-68.

Van Dijk, Teun. 1995. Prensa, racismo y poder. México: Universidad Iberoamericana.

Villaveces, Juanita Y Rodríguez, Paul. 2010. "Caricatura: Reflejo irónico de la realidad en Colombia”. Ciencia y desarrollo. 10: 1-8. 
